\title{
Cardiovascular response to exercise in diabetic patients: influence of autonomic neuropathy of different severity
}

\author{
P. Bottini ${ }^{1}$, C. Tantucci ${ }^{2}$, L. Scionti ${ }^{1}$, M. L.Dottorini ${ }^{1}$, E. Puxeddu ${ }^{1}$, G. Reboldi ${ }^{1}$, G. B. Bolli ${ }^{1}$, G. Casucci $^{1}$, \\ F.Santeusanio ${ }^{1}$, C. A. Sorbini ${ }^{2}$, P. Brumetti ${ }^{1}$ \\ ${ }^{1}$ Istituto di Medicina Interna e Scienze Endocrine e Metaboliche, Perugia, Italy \\ ${ }^{2}$ Istituto di Semeiotica e Metodologia Medica, Ancona, Italy
}

Summary We investigated cardiovascular function and plasma catecholamine response during incremental exercise and recovery in diabetic patients with (DAN+) and without autonomic neuropathy (DAN-). The former group was divided according to the presence of parasympathetic (DAN+PH-) or associated parasympathetic and sympathetic (DAN+PH+) damage to the autonomic nervous system. A group of healthy volunteers was studied as a control group. All the patients and control subjects underwent a submaximal or symptom-limited incremental exercise test using a cycle-ergometer. Air flow and respiratory gas fractions were sampled at the level of the mouth allowing a breath-by-breath analysis of oxygen consumption $\left(\mathrm{VO}_{2}\right)$. Heart rate and systolic blood pressure were recorded and venous blood samples were obtained from the patients at rest and during each minute of exercise and recovery to measure norepinephrine and epinephrine plasma levels. Haemodynamic parameters and plasma catecholamines were computed at rest and at 25, 50, 75 and $100 \%$ of the peak $\mathrm{VO}_{2}\left(\mathrm{VO}_{2 \max }\right)$. The breathby-breath relationships among $\mathrm{VO}_{2}$, heart rate and $\mathrm{VO}_{2}$ /heart rate against work were assessed during exercise for patients and control subjects. While $\mathrm{VO}_{2 \max }$ in absolute values was not significantly different among the diabetic groups, $\mathrm{VO}_{2 \max }$ was much less in diabetic patients than in control subjects $(p<0.01)$. During exercise the rate of heart rate, systolic blood pressure, norepinephrine and epinephrine increase was different among the diabetic groups, being significantly blunted in $\mathrm{DAN}+\mathrm{PH}+$. The $\mathrm{VO}_{2}$ /work relationship of the three diabetic groups was similar but markedly reduced in respect to that of control subjects $(p<0.001)$. The relationship between oxygen pulse ( $\mathrm{VO}_{2}$ /heart rate) and work showed no differences among the diabetic groups, whereas its slope was significantly steeper in control subjects $(p<0.01$ vs $\mathrm{DAN}-; p<0.05$ vs $\mathrm{DAN}+\mathrm{PH}-$ and $\mathrm{DAN}+\mathrm{PH}+$ ). In conclusion during incremental exercise both $\mathrm{DAN}+\mathrm{PH}-$ and $\mathrm{DAN}+\mathrm{PH}+$ exhibit abnormal heart rate, systolic blood pressure and catecholamine responses which, however, appear clearly distinct between the two groups of DAN+. In DAN+ the $\mathrm{VO}_{2}$ increment is reduced during exercise. Since DANshow the same impairment, this particular finding seems most likely to be influenced by factors (i.e.: diabetic cardiomyopathy) other than overt autonomic neuropathy. [Diabetologia (1995) 38: 244-250]

Key words Exercise, diabetic autonomic neuropathy, postural hypotension, cardiovascular response, catecholamines, diabetic cardiomyopathy.
Received: 11 March 1994 and in revised form: 25 August 1994

Corresponding author: Dr. P. Bottini, Istituto di Medicina Interna e Scienze Endocrine e Metaboliche, University of Perugia, Via E. Dal Pozzo, I-06126, Perugia, Italy

Abbreviations: C, Control subjects; DAN-, diabetic patients without autonomic neuropathy; $\mathrm{DAN}+$, diabetic patients with autonomic neuropathy; $\mathrm{DAN}+\mathrm{PH}-$, diabetic patients with au- tonomic neuropathy without postural hypotension; $\mathrm{DAN}+\mathrm{PH}+$, diabetic patients with autonomic neuropathy with postural hypotension; $\mathrm{V}_{\mathrm{E}}$, minute ventilation; $\mathrm{VO}_{2}$, oxygen consumption; $\mathrm{VCO}_{2}$, carbon dioxide production; $\mathrm{AT}$, anaerobic threshold; $\mathrm{SaO}_{2}$, arterial oxygen saturation; $\mathrm{HR}$, heart rate; SBP, systolic blood pressure; CW, cardiac work; $\mathrm{VO}_{2 \text { max }}$, peak $\mathrm{VO}_{2}$. 
Table 1. Clinical features of the subjects studied. DAN-: subjects without autonomic neuropathy; DAN+PH-: subjects with diabetic autonomic neuropathy, but without postural hy-

\begin{tabular}{|c|c|c|c|c|}
\hline Group & $\mathrm{DAN}-$ & $\mathrm{DAN}+\mathrm{PH}-$ & $\mathrm{DAN}+\mathrm{PH}+$ & $\mathrm{C}$ \\
\hline Age (years) & $43 \pm 3.3$ & $44 \pm 3.1$ & $37 \pm 3.1$ & $36 \pm 2.0$ \\
\hline Height $(\mathrm{cm})$ & $170 \pm 2.4$ & $169 \pm 2.7$ & $173 \pm 2.3$ & $175 \pm 1.8$ \\
\hline Smoking habit & $5 \mathrm{~S} / 2 \mathrm{ES} / 3 \mathrm{NS}$ & $2 \mathrm{~S} / 3 \mathrm{ES}$ & 2S/1ES/2NS & $5 \mathrm{~S} / 2 \mathrm{ES} / 3 \mathrm{NS}$ \\
\hline Pack years in $S$ & $10.0 \pm 5.1$ & $27.0 \pm 17.0$ & $15.0 \pm 10.0$ & $20.2 \pm 2.1$ \\
\hline Autonomic neuropathy score & $0.6 \pm 0.2$ & $4.8 \pm 0.2$ & $7.0 \pm 0.3$ & \\
\hline $\mathrm{HbA}_{1 \mathrm{c}} \mathrm{a}(\%)$ & $7.1 \pm 0.2$ & $7.6 \pm 0.5$ & $8.0 \pm 0.7$ & \\
\hline
\end{tabular}

potension; $\mathrm{DAN}+\mathrm{PH}+$ : subjects with severe autonomic neuropathy including postural hypotension; C, control subjects; S, smokers; ES, ex-smokers; NS, non-smokers

${ }^{a}$ Values in non-diabetic subjects: $3.8-5.5 \%$

In recent years, several studies have examined the cardiovascular response to exercise in diabetic patients with autonomic neuropathy [1-6]. Dysfunction of the parasympathetic as well as orthosympathetic nervous system [1], abnormal levels of plasma noradrenaline [2], and impaired cardiac and hepatosplanchnic vascular response [3] have been described in diabetic patients with autonomic neuropathy during graded exercise.

In these studies, however, the haemodynamic responses to exercise were generally described in diabetic patients who were heterogeneous with respect to the autonomic neuropathy. In fact these patients were considered as a whole group even though they were affected by only predominant parasympathetic or combined parasympathetic and sympathetic autonomic neuropathy $[1,2,4-6]$.

At rest, the haemodynamics of diabetic patients with combined parasympathetic and sympathetic autonomic neuropathy differ from those of patients with predominant parasympathetic autonomic neuropathy $[7,8]$. During effort, in the only study in which this distinction was made, the cardiovascular response to exercise was evaluated exclusively at two fixed workloads in a steady-state condition [3]. To extend these observations [1-8], we investigated the cardiovascular function and the plasma catecholamine response during incremental exercise and recovery in diabetic patients with and without autonomic neuropathy. The former were accurately divided according to the presence of parasympathetic only or the associated parasympathetic and sympathetic damage to the autonomic nervous system.

\section{Materials and methods}

Subjects. Twenty male diabetic patients, 10 without (DAN-) and 10 with $(\mathrm{DAN}+)$ diabetic autonomic neuropathy were recruited from the Istituto di Medicina Interna e Scienze Endocrine e Metaboliche of University of Perugia and enrolled in the study after they had given fully informed consent. The pro- tocol was approved by the local ethical committee and was in accordance with the Helsinki Declaration.

All patients were on treatment with regular insulin prior to each meal and intermediate-acting insulin at bedtime. No drugs able to influence the cardiovascular function, in particular angiotensin converting enzyme (ACE) inhibitors, were being taken by the patients. Autonomic neuropathy was assessed by the standard cardiovascular tests [10]; each test was scored according to the literature [11] and the patients were considered positive for autonomic neuropathy if the total score was equal to or greater than 4 . Five out of 10 patients with DAN+ had postural hypotension. All 5 patients showed baseline levels of plasma catecholamines at the lower levels of the normal range of our laboratory. Henceforth these DAN+ patients will be referred to as $\mathrm{DAN}+\mathrm{PH}+$ whereas the remaining $5 \mathrm{DAN}+$ patients without postural hypotension and with normal baseline plasma levels of catecholamines will be referred to as $\mathrm{DAN}+\mathrm{PH}-$.

In the $\mathrm{DAN}+\mathrm{PH}+$ group, 2 subjects had pre-proliferative retinopathy; in the $\mathrm{DAN}+\mathrm{PH}-$ group, 1 subject had proliferative retinopathy; 4 out of $10 \mathrm{DAN}$ - subjects had background retinopathy. As to symptoms related to autonomic dysfunction only one subject $\mathrm{DAN}+\mathrm{PH}+$ complained of nocturnal watery diarrhoea. None of the patients studied was suffering from anaemia or had signs or symptoms of endocrine or metabolic diseases other than diabetes. All patients were normotensive and none of them had evidence of ischaemic heart disease or $\mathrm{S}-\mathrm{T}$ segment depression during previous submaximal or symptom-limited incremental exercise. To rule out the presence of either dilated or restrictive cardiomyopathy or valvular heart disease, a bidimensional echocardiographic study was performed in each patient. At rest, no left ventricular systolic or diastolic dysfunction was found and morphological and/or functional valvular abnormalities were excluded. None of the patients were involved in physical training programmes. Ten normal male subjects recruited from University staff, ageand weight-matched, were studied as a control group (C). The clinical characteristics of the study subjects are listed in Table 1 .

Study design. Both patients and control subjects underwent a submaximal (until $90 \%$ of maximum predicted heart rate) or symptom-limited, incremental exercise test, using a computerdriven, electrically-braked cycle-ergometer (Mijnhardt, Kem3 , The Netherlands). The subjects were also monitored after cessation of the effort (recovery period).

Hypoglycaemia was carefully prevented in patients during the $24 \mathrm{~h}$ prior to the study. Each exercise test was performed in the afternoon between 17.00 and 17.30 hours, $5 \mathrm{~h}$ after the 
Table 2. Workload and oxygen uptake $\left(\mathrm{VO}_{2}\right)$ at peak of exercise and anaerobic threshold (AT) values. DAN-, subjects without autonomic neuropathy; $\mathrm{DAN}+\mathrm{PH}-$, subjects with dia-

Group

\begin{tabular}{|c|c|c|c|c|}
\hline Group & $\mathrm{DAN}-$ & $\mathrm{DAN}+\mathrm{PH}-$ & $\mathrm{DAN}+\mathrm{PH}+$ & $\mathrm{C}$ \\
\hline Workload max (Watt) & $153 \pm 5.1$ & $153 \pm 13.4$ & $131 \pm 5.1$ & $187 \pm 9.4^{\mathrm{a}}$ \\
\hline Workload $\max$ (\% pred.) & $85.9 \pm 4.8$ & $86 \pm 3.2$ & $67.2 \pm 5.3^{b}$ & $85.6 \pm 3.0$ \\
\hline $\mathrm{VO}_{2 \max }(\mathrm{ml} / \mathrm{min})$ & $1927 \pm 102$ & $1845 \pm 194$ & $1629 \pm 147$ & $2606 \pm 133^{c}$ \\
\hline $\mathrm{VO}_{2 \max }(\%$ pred.) & $80.7 \pm 3.6$ & $76.7 \pm 5.3$ & $64.4 \pm 6.1^{d}$ & $92.6 \pm 3.4^{\mathrm{c}}$ \\
\hline $\mathrm{AT}(\mathrm{ml} / \mathrm{min})$ & $951 \pm 48$ & $1047 \pm 134$ & $908 \pm 60$ & $1203 \pm 53^{\mathrm{e}}$ \\
\hline $\mathrm{AT}\left(\% \mathrm{VO}_{2 \max }\right)$ & $49.7 \pm 2.1$ & $56.8 \pm 3.5$ & $56.8 \pm 3.8$ & $48.1 \pm 1.9$ \\
\hline
\end{tabular}

${ }^{\mathrm{a}} p<0.01$ vs $\mathrm{DAN}-$ and $\mathrm{DAN}+\mathrm{PH}+, p<0.03$ vs $\mathrm{DAN}+\mathrm{PH}-$

${ }^{\mathrm{b}} p<0.02$ vs $\mathrm{C}$ and $\mathrm{DAN}-, p<0.05$ vs DAN $+\mathrm{PH}-$

${ }^{c} p<0.01$ vs DAN-, DAN+PH- and DAN+PH+

betic autonomic neuropathy, but without postural hypotension; $\mathrm{DAN}+\mathrm{PH}+$, subjects with severe autonomic neuropathy including postural hypotension; $\mathrm{C}$, controls

patients had taken their regular insulin dose at lunch. A G-18 teflon catheter was inserted into a superficial vein of the forearm of diabetic patients, allowing blood sampling. After 15min rest, both patients and control subjects sustained a 2 -min period of loadless pedalling and then cycled at $60 \mathrm{rev} / \mathrm{min}$ with an incremental load of $0.33 \mathrm{watt} / \mathrm{s}(20 \mathrm{watts} / \mathrm{min}$ ramping). While wearing a nose-clip all of them breathed through a mouthpiece into a two-way breathing valve. Expiratory air flow was measured by a pneumotachograph and expired volume was obtained integrating for the time, while the air was continuously sampled at the mouth for determining inhaled and expiratory gas concentrations, allowing a breath-bybreath analysis of oxygen consumption $\left(\mathrm{VO}_{2}\right)$ and carbon dioxide production $\left(\mathrm{VCO}_{2}\right)(\mathrm{CPX}$ system, Medical Graphics $\mathrm{Co}$, St Paul, Minn, USA). If detectable, the gas exchange anaerobic threshold (AT) was determined, according to the $\mathrm{V}$ slope method, by means of the computer-resident algorithm or by eye, in the absence of an automatically defined AT.

Heart rate (HR) was measured by ECG tracings at rest by averaging values from at least two 1-min periods of recording and during exercise by computing mean values from the last $20 \mathrm{~s}$ of each 1 -min period of incremental load and recovery. The heart rate signal was sent to the computer and oxygen pulse $\left(\mathrm{VO}_{2} / \mathrm{HR}\right)$ could be calculated for each breath. Systolic blood pressure (SBP) was always recorded by the same investigator using a stethoscope, a mercury sphygmomanometer and a cuff, at rest and each minute during exercise and recovery.

Venous blood samples were drawn from the patients to measure epinephrine and norepinephrine plasma levels at rest and at each minute of exercise and recovery. The blood samples were immediately placed on ice until centrifugation and storage of plasma at $-20^{\circ} \mathrm{C}$ could be performed. Later, analysis was carried out using the HPLC method [13]. Plasma glucose concentration was measured at rest and at the end of the recovery phase in patients by means of a Beckman Glucose Analyzer (Beckman Instruments, Fullerton, Calif., USA). For ethical reasons blood samples were not obtained from control subjects. The haemodynamic parameters and plasma catecholamine values were computed at rest and at $25,50,75$ and $100 \%$ of the peak $\mathrm{VO}_{2}\left(\mathrm{VO}_{2} \max \right)$. Also, the breath-by-breath relationship among $\mathrm{VO}_{2}, \mathrm{HR}$ and $\mathrm{VO}_{2} / \mathrm{HR}$ against work during exercise were assessed for patients and controls.

\section{Statistical analysis}

The means of the groups were compared by using the analysis of variance (ANOVA) and orthogonal comparisons adopting a two-tailed Student's $t$-test for unpaired data when allowed
${ }^{\mathrm{d}} p<0.03$ vs DAN-

${ }^{e} p<0.01$ vs DAN- and DAN+PH+

by ANOVA. The time-course analysis of the parameters was performed by analysis of variance corrected for repeated measures. Linear correlations were calculated by means of the least square method [14]. Data are expressed as mean \pm SEM.

\section{Results}

Workload and oxygen consumption. The maximum workload and peak $\mathrm{VO}_{2}$ (here referred to as $\mathrm{VO}_{2}$ max ) achieved by the diabetic patients and control subjects are displayed in Table 2 .

$C$ reached higher absolute values of maximum workload; however, C, DAN- and DAN+PH- performed a similar maximum workload, as percent of predicted, significantly higher than that of $\mathrm{DAN}+\mathrm{PH}+$. Peak $\mathrm{VO}_{2}$ was much lower in diabetic patients than in $\mathrm{C}$, both in absolute values and as percent of predicted $(p<0.01)$. In this respect, $\mathrm{DAN}+\mathrm{PH}+$ had a reduced $\mathrm{VO}_{2}$ max , as percent of predicted, in comparison with $\mathrm{DAN}-(p<0.03)$. The patients who stopped exercise because of symptoms referred dyspnea, muscular exhaustion or both; but no episodes of chest pain, ischaemic ECG alterations or arrythmias occurred. None of the diabetic patients suffered from hypoglycaemia during exercise.

Heart rate. HR for the three diabetic groups and control subjects was displayed in respect to $\mathrm{VO}_{2}$ in Figure 1 . The resting $\mathrm{HR}$ was significantly higher in $\mathrm{DAN}+\mathrm{PH}-(p<0.05)$; however, at $100 \%$ of $\mathrm{VO}_{2} /$ $\mathrm{VO}_{2} \max \mathrm{HR}$ was markedly lower in $\mathrm{DAN}+\mathrm{PH}+$ $(p<0.05)$. The slope (b) of the linear regression between $\mathrm{HR}$ and $\mathrm{VO}_{2} / \mathrm{VO}_{2} \max \%$ was significantly less in $\mathrm{DAN}+\mathrm{PH}+\left(\mathrm{b}=0.40 \pm 0.12\right.$ beat $\min ^{-1} \cdot \%{ }^{-1}$; $p<0.01)$ and $\mathrm{DAN}+\mathrm{PH}-(\mathrm{b}=0.47 \pm 0.03$ beat $\left.\min ^{-1} . \%-1 ; p<0.01\right)$ than in $\mathrm{DAN}-(\mathrm{b}=0.76 \pm 0.03$ beat $\left.\cdot \min ^{-1} \cdot \%-1\right)$ and in $C(b=0.81 \pm 0.05$ beat . $\left.\min ^{-1} \cdot \%^{-1}\right)$. During recovery, HR did not decrease further after $6 \mathrm{~min}$ in $\mathrm{DAN}+\mathrm{PH}-$ and $\mathrm{DAN}+\mathrm{PH}+$, in contrast to DAN- and C groups (Fig. 1).

Systolic blood pressure. The SBP value at peak of exercise was remarkably lower in $\mathrm{DAN}+\mathrm{PH}+(p<0.05$ 


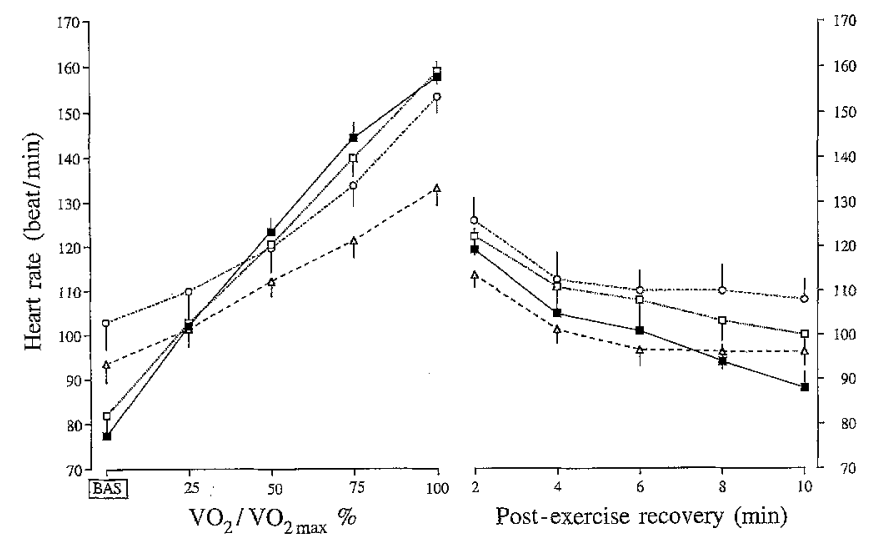

Fig. 1. Heart rate in response to exercise (expressed as percent of maximal $\mathrm{VO}_{2}$ uptake) and its recovery in the three groups of insulin-treated diabetic subjects and in the control group $[\mathrm{DAN}-(\square), \mathrm{DAN}+\mathrm{PH}-(\mathrm{O}), \mathrm{DAN}+\mathrm{PH}+(\Delta), \mathrm{C}(\boldsymbol{\square})]$. During exercise (left side) heart rate increased in all groups with a different time course among diabetic groups $(p<0.001)$

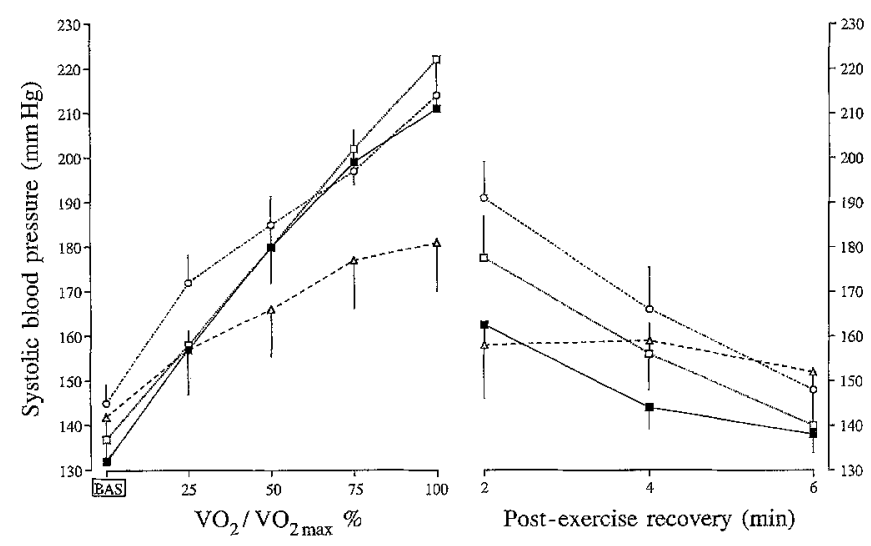

Fig. 2. Systolic blood pressure in response to exercise (expressed as percent of maximal $\mathrm{VO}_{2}$ uptake) and its recovery in the three groups of insulin-treated diabetic subjects and in the control group [DAN- ( $\square)$, DAN + PH- (O), DAN+ $\mathrm{PH}+(\Delta), \mathrm{C}(\boldsymbol{\square})]$. During exercise systolic blood pressure increased in all groups with a different time course among diabetic groups $(p<0.01)$ (left side). The recovery time course was significantly different among diabetic groups $(p<0.01)$

vs $\mathrm{C}$ and the two other diabetic groups) (Fig.2). According to the slope (b) of the linear relationship between SBP and $\mathrm{VO}_{2} / \mathrm{VO}_{2}$ max $\%$, the rate of SBP increase during effort was significantly lower in $\mathrm{DAN}+\mathrm{PH}+(\mathrm{b}=0.39 \pm 0.07 \mathrm{mmHg} / \%)$, than in $\mathrm{C}$ $(\mathrm{b}=0.80 \pm 0.06 \mathrm{mmHg} / \% ; p<0.001)$, DAN- $(\mathrm{b}=$ $0.86 \pm 0.04 \mathrm{~mm} \mathrm{Hg} / \% ; p<0.001)$ and $\mathrm{DAN}+\mathrm{PH}-$ $(\mathrm{b}=0.66 \pm 0.10 \mathrm{~mm} \mathrm{Hg} / \% ; p<0.05)$. After exercise $\mathrm{SBP}$ rapidly decreased in $\mathrm{DAN}-$ and $\mathrm{DAN}+\mathrm{PH}-$, as in $C$, reaching the pre-exercise values after $6 \mathrm{~min}$ of recovery, while in $\mathrm{DAN}+\mathrm{PH}+$ group, after an initial fall, SBP remained unchanged and consistently higher than that of the others groups, at least until 6 min of recovery.

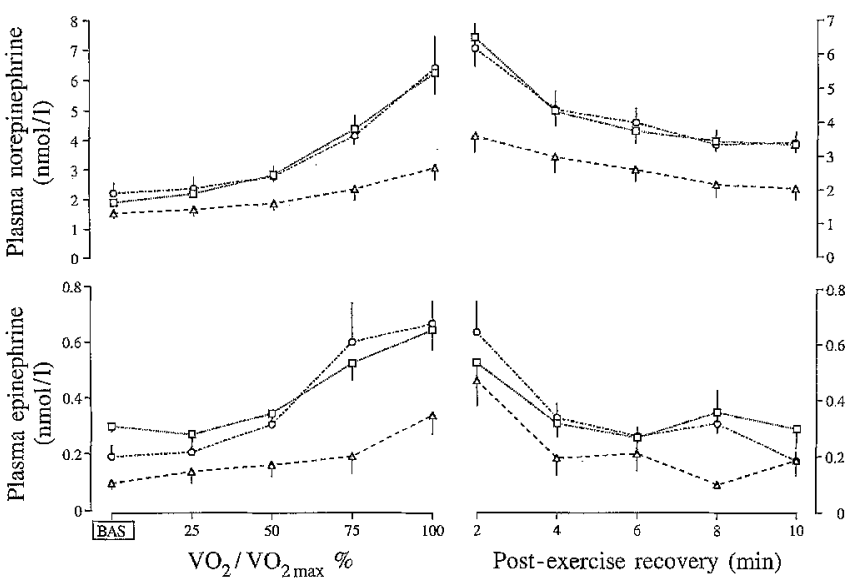

Fig. 3. Plasma norepinephrine (top) and epinephrine (bottom) concentrations in response to exercise (expressed as percent of maximal $\mathrm{VO}_{2}$ uptake) and its recovery in the three groups of insulin-treated diabetic subjects [DAN- $(\square), \mathrm{DAN}+\mathrm{PH}-(0)$, $\mathrm{DAN}+\mathrm{PH}+(\Delta)]$. During exercise norepinephrine increased with a different time course among diabetic groups $(p<0.05)$. Throughout the recovery phase norepinephrine remained lower in $\mathrm{DAN}+\mathrm{PH}+$ than in the two other groups. During exercise epinephrine increased in all groups with a different time course $(p<0.05)$; after exercise epinephrine decreased in all groups

Plasma catecholamines. At rest, plasma norepinephrine (NE) concentration was lower in $\mathrm{DAN}+\mathrm{PH}+$ $(1.56 \pm 0.16 \mathrm{nmol} / \mathrm{l})$ than in $\mathrm{DAN}+\mathrm{PH}-(1.92 \pm$ $0.11 \mathrm{nmol} / \mathrm{l})$ and in DAN- $(2.24 \pm 0.3 \mathrm{nmol} / \mathrm{l})(p<$ 0.01 ). During effort the NE increase was deeply blunted at each observed level of exercise for DAN+PH+. In $\mathrm{DAN}+\mathrm{PH}+\mathrm{NE}$ was lower than in the two other groups throughout the recovery phase (Fig. 3).

Pre-exercise plasma epinephrine (E) was lower in $\mathrm{DAN}+\mathrm{PH}+(0.10 \pm 0.02 \mathrm{nmol} / \mathrm{l})$ as compared to DAN $-(0.30 \pm 0.02 \mathrm{nmol} / \mathrm{l})$ and $\mathrm{DAN}+\mathrm{PH}-(0.20 \pm$ $0.04 \mathrm{nmol} / 1)$. In response to exercise $E$ increased much less in $\mathrm{DAN}+\mathrm{PH}+$ as compared to $\mathrm{DAN}-$ and $\mathrm{DAN}+\mathrm{PH}-(p<0.05)$. After exercise $\mathrm{E}$ decreased similarly in all three groups.

Relationship between $\mathrm{VO}_{2}$ uptake, oxygen pulse ( $\mathrm{VO}_{2}{ }^{\prime}$ $H R$ ), heart rate (HR) and work. The $\mathrm{VO}_{2}$ increase per unit of power was not dissimilar among the three diabetic groups, amounting to $8.7 \pm 0.4 \mathrm{ml} / \mathrm{min}$ for $\mathrm{DAN}-, 8.2 \pm 0.6 \mathrm{ml} / \mathrm{min}$ for $\mathrm{DAN}+\mathrm{PH}-$ and $7.6 \pm$ $0.5 \mathrm{ml} / \mathrm{min}$ for $\mathrm{DAN}+\mathrm{PH}+(p=0.08$ vs DAN -$)$, but it was markedly reduced $(p<0.001)$ in respect to that of C equal to $10.8 \pm 0.3 \mathrm{ml} / \mathrm{min}$ (Fig. 4 , panel A). The relationship between oxygen pulse $\left(\mathrm{VO}_{2} / \mathrm{HR}\right)$, which reflects the product between stroke volume and arterialvenous blood difference in oxygen content, and work did not show differences among the three groups of diabetic patients, whereas in $\mathrm{C}$ it was significantly steeper $(p<0.01$ vs DAN-; $p<0.05$ vs DAN+PHand DAN $+\mathrm{PH}+$ ) (Fig. 4, panel B). The heart rate increment with increasing work was reduced in $\mathrm{DAN}+\mathrm{PH}-(p<0.05$ vs $\mathrm{C}, p<0.02$ vs $\mathrm{DAN}-)$ and 

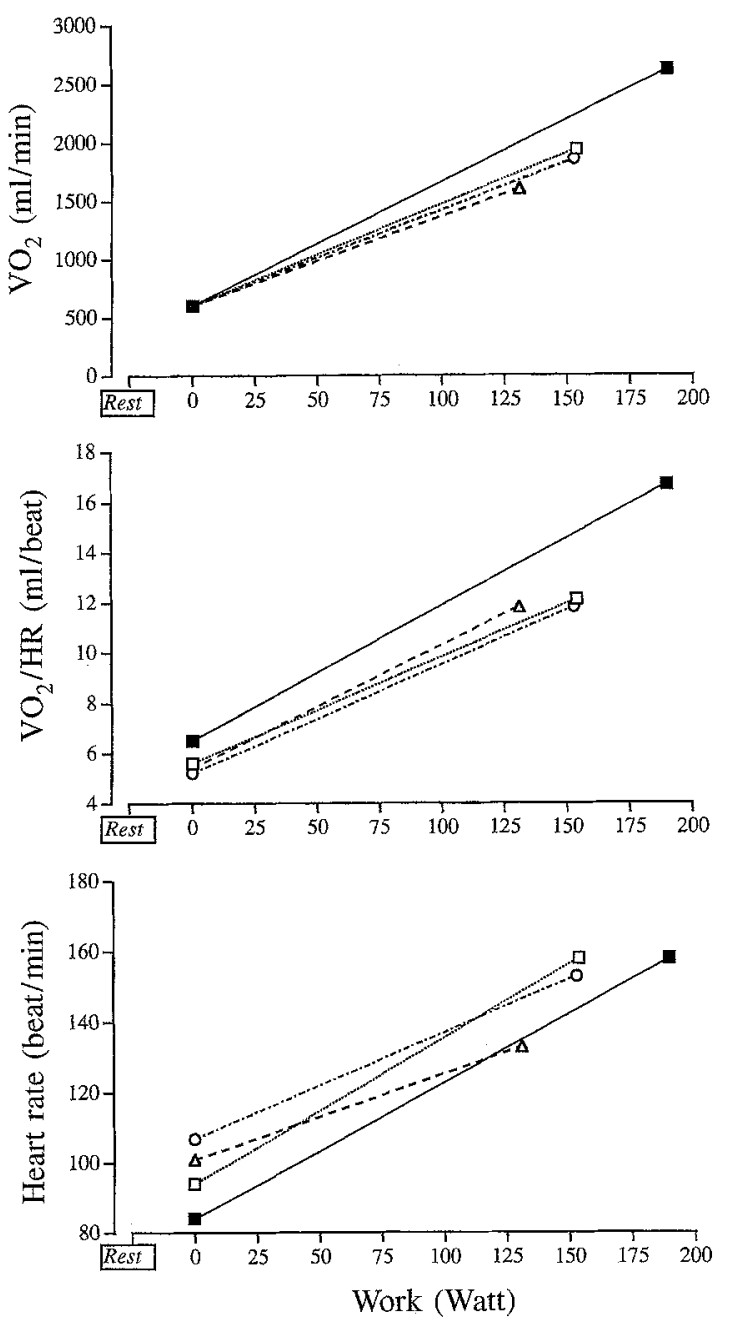

Fig. 4. Relationship between $\mathrm{VO}_{2}$ uptake and work (panel A), $\mathrm{VO}_{2} / \mathrm{HR}$ and work (panel B) and $\mathrm{HR}$ and work (panel C) in the three groups of insulin-treated diabetic subjects and in the control group $[\mathrm{DAN}-(\square), \mathrm{DAN}+\mathrm{PH}-(\mathrm{O}), \mathrm{DAN}+\mathrm{PH}+(\Delta)$, C (iv)]

was much lower in $\mathrm{DAN}+\mathrm{PH}+(p<0.01$ vs $\mathrm{C}$ and vs DAN-) when compared with those of $\mathrm{C}$ and DANwhich were essentially similar (Fig. 4, panel C).

Plasma glucose. At rest plasma glucose was similar in the three groups of diabetic patients $(12.8 \pm 0.7$, $12.1 \pm 0.5$ and $12.0 \pm 1.5 \mathrm{mmol} / \mathrm{l}$, for DAN-, DAN+ $\mathrm{PH}-$ and $\mathrm{DAN}+\mathrm{PH}+$, respectively). Plasma glucose decreased slightly at the end of the recovery period in each group without significant differences from the pre-exercise values.

\section{Discussion}

This study contributes to elucidating two main aspects of exercise performance in diabetes.

First, patients with long-standing diabetes, irrespective of the presence of autonomic neuropathy, exhibited a reduced maximal exercise capacity in terms of $\mathrm{VO}_{2 \text { max }}$ compared with control subjects during incremental exercise, for similar levels of percent predicted maximum workload. Actually, the $\mathrm{VO}_{2}$ increase per unit of power was not dissimilar among the three diabetic groups, but it was markedly reduced with respect to that of $\mathrm{C}$.

Hilsted et al. [3] measured a significantly lower stroke volume during exercise in $\mathrm{DAN}+\mathrm{PH}-$ and $\mathrm{DAN}+\mathrm{PH}+$ than in a control group, associated with a reduction of cardiac output increase. They concluded that an impaired myocardial contractility, resulting either from a diminished cardiac adrenergic stimulation or diabetic cardiomyopathy or both, was responsible for this finding.

Our data indirectly support this interpretation but extend it to the DAN-group. In fact, examination of the relationship between $\mathrm{VO}_{2} / \mathrm{HR}$ and work during exercise showed that no differences existed among the three groups of diabetic patients, whereas in $\mathrm{C}$ its slope was significantly steeper. Hence, in the absence of ischaemic alterations and manifest echocardiographic abnormalities at rest, the depressed $\mathrm{VO}_{2}$ vs work relationship, shown by all groups of diabetic patients during incremental exercise, would seem to be more closely related to metabolic and functional changes (i.e. decreased myocardial contractility and/or reduction in preload due to diminished left ventricular compliance) possibly linked to diabetic cardiomyopathy per se and not to sympathetic nerve degeneration. Systolic time intervals are frequently abnormal in diabetic patients [15] and a high frequency of diastolic dysfunction has been shown by pulsed Doppler echocardiography in young diabetic patients [16]. In our patients no cardiac abnormalities were recognized by B-mode echocardiography at rest, but it is conceivable that some degree of ventricular dysfunction could be elicited by stressful exercise. In this respect it should be emphasized that radionuclide studies have generally shown normal ejection fraction at rest but a lower ejection fraction in response to dynamic exercise in young patients with asymptomatic diabetes [17]. Experimental animal studies support the view that the diabetic state itself affects ventricular performance $[18,19]$.

It should be stressed, however, that the reduction of adrenergic support of the heart in $\mathrm{DAN}+\mathrm{PH}+$ adds a further disadvantage, because the decrease of myocardial contractility and the blunted cardiac acceleration contribute to a more severe impairment of cardiac output increase and $\mathrm{VO}_{2}$ increment during exercise. Indeed, the rate of heart rate increase with work which was normal for DAN-, appeared already depressed in $\mathrm{DAN}+\mathrm{PH}-$ and was greatly reduced in DAN $+\mathrm{PH}+$.

Second, the haemodynamic responses to incremental exercise in diabetic patients with autonomic 
neuropathy exhibited distinct abnormalities which were markedly different between $\mathrm{DAN}+\mathrm{PH}-$ and $\mathrm{DAN}+\mathrm{PH}+$. In contrast to the work previously carried out by Hilstead et al. [3], in the present study the haemodynamic variables were evaluated at workloads expressed as $\mathrm{VO}_{2}$ in percent of $\mathrm{VO}_{2}$ max. This is an important point because, for a given type of exercise, the increased sympathetic outflow to the heart and resistance vessels is more closely related to the percentage of $\mathrm{VO}_{2}$ max than to the actual workload [9]. Because a given workload represents a greater percentage of $\mathrm{VO}_{2}$ max in DAN+ than in DAN- and in normal subjects [1], previous findings of haemodynamic [1] and plasma catecholamine [3] responses in DAN+ as compared with DAN- examined at fixed workloads are difficult to interpret and might well mask an impaired sympathetic outflow in DAN+.

Failure to suppress the vagal tone in the early part of exercise accounted for the initially subnormal increase of heart rate in both $\mathrm{DAN}+\mathrm{PH}-$ and $\mathrm{DAN}+\mathrm{PH}+$ as compared with DAN- and C. Since $\mathrm{DAN}+\mathrm{PH}-$ had a largely intact sympathetic nervous system, as indicated by the normal plasma norepinephrine response, they ultimately attained the same values of heart rate at $100 \%$ of $\mathrm{VO}_{2} / \mathrm{VO}_{2} \max \%$ than DAN- and C. On the other hand, impaired sympathetic outflow in $\mathrm{DAN}+\mathrm{PH}+$ accounted for the persistently lower increase of heart rate later on during exercise. These considerations might also explain the time course of heart rate during the recovery period, where the predominance of vagal tone is normally resumed. Similar behaviour has been observed in the post-exercise recovery period of hearttransplanted subjects who have no parasympathetic cardiac innervation [20]. The predominant parasympathetic neuropathy might also account for the greater increase of the systolic blood pressure in $\mathrm{DAN}+\mathrm{PH}-$ compared with $\mathrm{DAN}-$ during the first 2-6 min of exercise and the persistently higher systolic blood pressure during the recovery period, a finding similar to that of heart-transplanted subjects [21]. Because of the reduced norepinephrine response in $\mathrm{DAN}+\mathrm{PH}+$, peripheral and splanchnic vascular resistances could increase less in response to exercise [3], accounting for the subnormal rise of blood pressure in this group.

Interestingly, plasma levels of epinephrine were also reduced at rest and during exercise in $\mathrm{DAN}+\mathrm{PH}+$ as compared with the two other groups of diabetic patients, thus contributing to the lower increase of heart rate observed in $\mathrm{DAN}+\mathrm{PH}+$. A blunted release of epinephrine following exercise in diabetic patients with autonomic neuropathy had not been previously found. In fact, although it is wellknown that responses of plasma epinephrine to metabolic stimuli such as hypoglycaemia are generally blunted in insulin-dependent and non-insulin-depen- dent diabetes [22-24], previous studies have shown normal responses of plasma epinephrine to exercise $[25,26]$, suggesting a selective defect to the hypoglycaemic stimulus.

In this study plasma insulin was not measured. Since therapeutic hyperinsulinaemia influences the sympathetic nervous system activity [8], it is possible that the haemodynamic responses would have been different if exercise had been performed under conditions of greater hyperinsulinaemia, i.e. $1-2 \mathrm{~h}$ after the subcutaneous insulin injection $[8,23]$. This is not the case $5 \mathrm{~h}$ after the prandial subcutaneous injection of regular insulin, when plasma insulin concentrations approach the values of the post-absorptive state in diabetes [23].

In conclusion, in DAN+PH-, heart rate is excessive at rest and during the early phase of exercise; as the effort progresses, the normal activation of the sympathetic autonomic nervous system allows these patients to develop virtually normal haemodynamic responses. Conversely, in DAN+PH+ the deficiency of the sympathetic autonomic nervous system outflow prevents an adequate response in terms of heart rate and systolic blood pressure increase during each phase of exercise.

Furthermore, in both groups of $\mathrm{DAN}+\mathrm{VO}_{2}$ increases subnormally with work, most likely because of a diminished increase in cardiac output. Since DAN - show the same impairment, this particular aspect seems more influenced by other factors rather than by the presence of autonomic nervous system damage. Although instrumental evidence of diabetic cardiomyopathy is lacking in these patients, the data of the present study indirectly support the hypothesis that this disorder can play a substantial role in limiting the exercise performance of diabetic patients.

Acknowledgements. The dedicated editorial help of Ms. G. Hoddle Stoppini and the superb technical assistence of Ms. R. Fraboni and Mr. G. Cipiciani are gratefully acknowledged.

\section{References}

1. Hilsted J, Galbo H, Christensen NJ (1979) Impaired cardiovascular responses to graded exercise in diabetic autonomic neuropathy. Diabetes 28: 313-319

2. Hilsted J, Galbo H, Christensen NJ (1980) Impaired responses of catecholamines, growth hormone, and cortisol to graded exercise in diabetic autonomic neuropathy. Diabetes 29:257-262

3. Hilsted J, Galbo H, Christensen NJ, Parving H-H, Benn J (1982) Haemodynamic changes during graded exercise in patients with diabetic autonomic neuropathy. Diabetologia 22: 318-323

4. Kahn JK, Zola B, Juni JE, Vinik AI (1986) Decreased exercise heart rate and blood pressure response in diabetic subjects with cardiac autonomic neuropathy. Diabetes Care 9: 389-394 
5. Roy TM, Peterson HR, Snider HL et al. (1989) Autonomic influence on cardiovascular performance in diabetic subjects. Am J Med 87: 382-388

6. Irace L, Iarussi D, Langella S, Sanrangelo L, Coppola V, Iacono A (1991) Adattamenti cardiovascolari durante test da sforzo al cicloergometro in diabetici insulino-dipendenti con e senza cardiopatia autonomica. Cardiologia 36: 611-617

7. Hilsted J, Parving H-H, Christensen NJ, Benn J, Galbo H (1981) Hemodynamics in diabetic orthostatic hypotension. J Clin Invest 68: 1427-1434

8. Porcellati F, Fanelli C, Bottini P et al. (1993) Mechanisms of arterial hypotension after therapeutic dose of subcutaneous insulin in diabetic subjects with and without autonomic neuropathy. Diabetes 42: 1055-1064

9. Rowell LB (1974) Human cardiovascular adjustments to exercise and thermal stress. Physiol Rev 54: 75-159

10. Ewing DJ, Clarke BF (1982) Diagnosis and management of diabetic autonomic neuropathy. BMJ 285: 916-918

11. Bellavere F, Bosello G, Fedele D, Cardone C, Ferri M (1983) Diagnosis and management of diabetic autonomic neuropathy. BMJ 287: 61

12. Wasserman K, Hansen JE, Sue DY, Whipp BJ (eds) (1987) Principles of exercise testing and interpretation. Lea \& Febiger, Philadelphia

13. Hjemdahl P, Daleskog M, Kahan T (1979) Determination of plasma catecholamines by high performance liquid chromatography with electrochemical detection: comparison with a radioenzymatic method. Life Sciences 25: 131-138

14. Zar J (1984) Biostatistical analysis. Prentice Hall Inc., Englewood Cliffs, NJ, pp 168-260

15. Seneviratne BI (1977) Diabetic cardiomyopathy: The preclinical phase. BMJ 1: 1444-1446

16. Zarich SW, Arbuckle BE, Cohen LR, Roberts M, Nesto RW (1988) Diastolic abnormalities in young asymptomatic diabetic patients assessed by pulse Doppler echocardiography. J Am Coll Cardiol 12: 114-120

17. Vered A, Battler A, Segal P et al. (1984) Exercise-induced left ventricular dysfunction in young men with asympto- matic diabetes mellitus (diabetic cardiomyopathy). Am J Cardiol 54: 633-637

18. Regan TJ, Ettinger PO, Kahn MI et al. (1974) Altered myocardial function and metabolism in chronic diabetes mellitus without ischemia in dogs. Circ Res 35: 222-237

19. Fein F, Strobeck JE, Malhotra A, Scheuer J, Sonnenblick EH (1981) Reversibility of diabetic cardiomyopathy with insulin in rats. Circ Res 49: 1251-1261

20. Savin WM, Haskell WL, Schroeder JS, Stinson EB (1980) Cardiorespiratory responses of cardiac transplant patients to graded, symptom limited exercise. Circulation 62: 5560

21. Ehrman J, Keteyian S, Fedel F et al. (1992) Cardiovascular responses of heart transplant recipients to graded exercise testing. J Appl Physiol 73: 260-264

22. Bolli G, Dimitriadis G, Pehling G et al. (1984) Abnormal glucose counterregulation after subcutaneous insulin in insulin-dependent diabetes mellitus. N Engl J Med 310: 1706-1711

23. Bolli G, Tsalikian E, Haymond MW et al. (1984) Defective glucose counterregulation after subcutaneous insulin in non-insulin dependent diabetes mellitus: paradoxical suppression of glucose utilization and lack of compensatory increase in glucose production, roles of insulin resistance, abnormal neuroendocrine responses, and islet paracrine interactions. J Clin Invest 73: 1532-1541

24. Dagogo-Jack S, Craft S, Cryer PE (1993) Hypoglycemia-associated autonomic failure in insulin-dependent diabetes mellitus. Recent antecedent hypoglycemia reduces autonomic responses to, symptoms of, and defense against subsequent hypoglycemia. J Clin Invest 91: 819-828

25. Hirsh BR, Shamoon H (1987) Defective epinephrine and growth hormone responses in type I diabetes are stimulus specific. Diabetes 36: 20-26

26. Rattarasarn C, Dagogo-Jack S, Cryer PE (1993) Hypoglycemia-associated autonomic failure is specific for the stimulus of hypoglycemia in IDDM. Diabetes 42: 80A (Abstract) 